\title{
Economic Benefits from Waste Management in Hotel Business: A Case Bangkok Thailand
}

\author{
Sumalee Pumpinyo1, Saowaluck Kuchareonpasit ${ }^{2}$ \\ Assistant Professor, Faculty of Economics, Kasetsart University, Bangkok, Thailand ${ }^{1}$ \\ Associate Professor, Faculty of Economics, Kasetsart University, Bangkok, Thailand ${ }^{2}$
}

\begin{abstract}
In the current era of Green Economy, green strategies like recycling of waste has a great potential to benefits the economy. Hotel industry constitute a significant solid waste management (SWM) problems, especially in urban areas like Bangkok, Thailand where waste generation from hotel industry has continuously increased due to increased number of visitors. Overall 9,873 tonnes/day or 3.603 million tonnes/year of waste is being generated in the Bangkok and out of that only $3 \%$ is incinerated, $10 \%$ is converted into fertilizers and remaining $87 \%$ goes to landfill. The hotel industry is one of the major contributor of organic/wet waste into landfills. Waste generated from hotels consists of recyclable waste and organic waste. This paper aims to examine the hotels based solid waste generation, its composition as well as its reuse and recycling. This study analyzed the economic feasibility of waste management projects employing methods such as recycling of organic waste materials through cost-benefit analysis. The benefits of waste recycling management projects are categorized as direct and indirect benefits. These project increase revenues from the sale of recyclable waste, and cost saving from use biogas produced from organic waste, from the use organic fertilizer produced as through project instead of purchasing chemical fertilizer, from bio-fermentative conversion of fruit waste to cleaning products via a proprietary process, from reduced municipal charges for disposal and management of food and solid wastes. The results show that waste recycling is economically feasible and suggests a better system for waste management.
\end{abstract}

Keywords: Waste Management, Hotel Waste Management, Feasibility 